\section{Analysis of Admission} Electrocardiographic Patterns in Survivors and Non-Survivors of Unprotected Left Main Acute Coronary Syndrome Undergoing Percutaneous Coronary

\section{Intervention}

\begin{abstract}
Introduction: The optimal treatment strategy for left ma in coronary artery disease continues to be debated. This is particularly evident for the high risk subgroup of patients presenting with acute coronary syndrome (ACS) and who are underrepresented in published tria ls. The electrocardiogram (ECG) represents one of the first line diagnostic tests for evaluating patients with possible ACS. Specific acute ECG abnormalities can raise the suspicion of significant left main (LM) involvement. Our aim, therefore, was to analyze the ECG pattems of ACS patients undergoing perc utaneous coronary intervention (PCI) of unprotected left main coronary artery (ULMCA) lesions.

Methods: Between February 2004 and December 2012 there were 67 patients with left main coronary stenosis (mean age $70 \pm 18$ years) who underwent acute $\mathrm{PCl}$. We retrospectively analyzed the patients' electronic charts and obtained data on personal history, medication, clinical status, cardiac biomarkers, electrocardiograms on admission, details of the performed coronary angiography with subsequent $\mathrm{PCl}$ and patient outc ome. In 25 of the patients the urgent $\mathrm{PCI}$ was performed on a protected vessel (post CABG with at least one functional graft to $L A D / L C X)$, and we excluded these patients.

Results: Follow-up data was available from 42 patients (100\%) The cumulative mortality rate (in hospital and at 6 months) in patients with acute interventions in symptomatic LMCA stenosis was $23.8 \%$ (10 patients). The most common ECG patterns were significant ST-segment elevation in lead aVR, significant ST-segment depression in leads V4V6, and first degree atrioventricular (AV) block.

Conclusion: In our analysis the most common ECG pattems in patients with acute coronary syndrome related to left main disease were significant ST-segment elevation in lead aVR, significant STsegment depression in leads V4-V6 and AV block. In this study with a small sample size and limited cases there were no specific ECG pattems on admission that were indic ative of an adverse outcome in ACS patients related to an unprotected left ma in culprit lesion.
\end{abstract}

\section{Background}

The optimal treatment strategy for left main coronary artery disease remains unresolved. This is particularly noticed in the high risk subgroup of patients presenting with acute coronary syndrome (ACS) and who are underrepresented in published trials. Recently a steady shift towards percutaneous coronary interventions (PCI)as opposed to surgical treatment with coronary artery bypass graft (CABG) - can be observed in the ACS population with left main

\section{Journal of}

\section{Cardiobiology}

Nazmi Krasniqi ${ }^{1,2}$, Stephanie Horisberger ${ }^{1}$, Patrick T. Siegrist ${ }^{1}$, Tobias A. Fuchs ${ }^{1,2}$, Ardan M. Saguner ${ }^{1}$, Frank Scherff ${ }^{1}$, Urs Eriksson ${ }^{1,2}$, Roberto Corti ${ }^{3}$ and Thomas F. Lüscher ${ }^{1 *}$

${ }^{1}$ Department of Cardiology, Cardiovascular Center, University Hospital Zurich, Switzerland

${ }^{2}$ Division of Cardiology, GZO-Zurich Regional Health Center, Wetzikon, Switzerland

${ }^{3}$ Heart Clinic Hirslanden Zurich, Switzerland

*Address for Correspondence

Thomas F. Lüscher, Director, Department of Cardiology, Cardiovascular Center, University Hospital Zurich, Raemistrasse 100, CH-8091 Zurich, Switzerland, Tel: +41 4425521 21; Fax: +41 4425544 01; E-mail: karlue@usz.uzh.ch

Copyright: (c) 2014 Krasniqi N, et al. This is an open access article distributed under the Creative Commons Attribution License, which permits unrestricted use, distribution, and reproduction in any medium, provided the original work is properly cited.

Submission: 20 December, 2013

Accepted: 20 March, 2014

Published: 25 March, 2014

Reviewed \& Approved by: Dr. MacArthur A Elayda, Department of Cardiovascular Epidemiology and Medical Informatics, Texas Heart Institute, USA

(LM) culprit lesions [1]. Notwithstanding recent reports of a better prognosis than expected in this particular patient population, mortality remains relatively high compared to elective interventions [2].

The electrocardiogram (ECG) represents one of the first line diagnostic tests for evaluating patients with possible ACS $[3,4]$. Specific acute phase ECG abnormalities can raise the suspicion of significant LM involvement. The so-called 'global ischemia' pattern-that is, diffuse ST-segment depression with inverted $\mathrm{T}$ waves particularly when associated with ST-segment elevation in lead aVR - predicts left main, left main equivalent, or three vessel disease and, more importantly, these alterations carry an adverse prognosis $[5,6]$.

We performed this retrospective analysis to identify possible specific ECG patterns on admission in survivors and non-survivors with ACS undergoing PCI of unprotected left main culprit lesions.

\section{Methods}

\section{Patients}

We performed a single-center retrospective analysis with data retrieved from the database of the catheterization laboratory of our institution (Cardiovascular Center of the University Hospital Zurich). We included all patients with ACS of any subtype undergoing urgent PCI treatment between February 2004 and December 2012 for an unprotected LM culprit lesion. To this end we reviewed the patients' electronic charts and obtained data on their personal history, medication, clinical status, cardiac biomarkers, electrocardiograms on admission, details of the coronary angiography that was performed and subsequent PCI, as well as outcome of 67 patients from the time of hospitalization to 6 months post discharge. In 25 patients the urgent PCI was performed on a protected vessel (by collateral coronary blood flow or post CABG with at least one functional graft 
Citation: Krasniqi N, Horisberger S, Siegrist PT, Fuchs TA, Saguner AM, et al. Analysis of Admission Electrocardiographic Patterns in Survivors and Non-Survivors of Unprotected Left Main Acute Coronary Syndrome Undergoing Percutaneous Coronary Intervention. J Cardiobiol. $2014 ; 2(2)$ : 5.

to LAD/LCX); these patients were excluded from the analysis.

For our analysis the following ECG abnormalities were taken into consideration: ST-segment elevation $\geq 0.1 \mathrm{mV}$ in $\geq 2$ contiguous leads of any location, ST-segment elevation $\geq 0.1 \mathrm{mV}$ in lead aVR, ST-segment depression $\geq 0.1 \mathrm{mV}$ in leads V4-V6, negative T-waves in lead aVL, atrioventricular (AV) block of any grade, complete and incomplete right bundle branch block (C-RBBB, IC-RBBB), and complete left bundle branch block (C-LBBB).

\section{Procedure}

The percutaneous coronary interventions were performed according to current guidelines. The procedures including optional techniques such as the use of intra-aortic balloon pump, the use of

Table 1: Baseline clinical characteristics.

\begin{tabular}{|c|c|c|c|}
\hline & Total $(n=42)$ & $\begin{array}{l}\text { Survivors } \\
(n=32)\end{array}$ & $\begin{array}{l}\text { Non- } \\
\text { Survivors } \\
(n=10)\end{array}$ \\
\hline $\begin{array}{l}\text { Demographic } \\
\text { characteristics }\end{array}$ & $42(100 \%)$ & $32(100 \%)$ & $10(100 \%)$ \\
\hline Age, y (mean, range) & $70(42-90)$ & $70(42-90)$ & $72.3(53-85)$ \\
\hline Sex $M$ & $30(71.4 \%)$ & $23(71.8 \%)$ & $7(70 \%)$ \\
\hline Sex W & $12(28.6 \%)$ & 9 (28.1\%) & $3(30 \%)$ \\
\hline \multicolumn{4}{|l|}{ Past medical history } \\
\hline Myocardial infarction & $16(38.1 \%)$ & $14(43.8 \%)$ & $2(20 \%)$ \\
\hline $\mathrm{PCl}$ & 9 (21.4\%) & 8 (25\%) & $1(10 \%)$ \\
\hline CABG & 0 & 0 & 0 \\
\hline $\begin{array}{l}\text { Chronic obstructive } \\
\text { pulmonary disease }\end{array}$ & $3(7.1 \%)$ & $2(6.25 \%)$ & $1(10 \%)$ \\
\hline Chronic renal failure & 7 (16.7.2\%) & $3(9.4 \%)$ & $4(40 \%)$ \\
\hline Cerebrovascular insult & $2(4.8 \%)$ & $1(3.1 \%)$ & $1(10 \%)$ \\
\hline \multicolumn{4}{|l|}{ Medication (at admission) } \\
\hline Aspirin & $24(57.1 \%)$ & $19(59.4 \%)$ & $5(50 \%)$ \\
\hline Clopidogrel & $13(31 \%)$ & $11(34.4 \%)$ & $2(20 \%)$ \\
\hline Abciximab/tirofiban & $2(4.8 \%)$ & $2(6.25 \%)$ & 0 \\
\hline Statin & $21(50 \%)$ & $16(50 \%)$ & $5(50 \%)$ \\
\hline $\begin{array}{l}\text { ACE inhibitor/AT II } \\
\text { antagonist }\end{array}$ & $14(33.3 \%)$ & $13(40.6 \%)$ & $1(10 \%)$ \\
\hline Beta-blocker & $18(42.8 \%)$ & $17(53.1 \%)$ & $1(10 \%)$ \\
\hline Ca-antagonist & $3(7.1 \%)$ & 2 (6.25\%) & $1(10 \%)$ \\
\hline \multicolumn{4}{|c|}{ Laboratory parameters (mean, range) } \\
\hline $\mathrm{CK} \max (\mathrm{U} / \mathrm{l})$ & $\begin{array}{l}2174(40- \\
13262)\end{array}$ & $\begin{array}{l}1788(40- \\
10675)\end{array}$ & \begin{tabular}{|l}
$3332(214-$ \\
$13262)$
\end{tabular} \\
\hline CK-MB (U/l) & $\begin{array}{l}235.6(7- \\
1402)\end{array}$ & $187.8(7-817)$ & $371(56-1402)$ \\
\hline Myoglobin (ng/ml) & $\begin{array}{l}1225(38- \\
9206)\end{array}$ & $650.5(38-2892)$ & $\begin{array}{l}2854(68- \\
9206)\end{array}$ \\
\hline Troponin $(\mu \mathrm{g} / \mathrm{l})$ & $9.1(0.2-79)$ & $5.8(0.2-24.3)$ & $16(0-79)$ \\
\hline Creatinine on admission & $104(57-254)$ & 92 (57-155) & $140(75-254)$ \\
\hline NT-proBNP (ng/l) & $\begin{array}{l}2827(99- \\
18814)\end{array}$ & $\begin{array}{l}2827(99- \\
18814)\end{array}$ & $\begin{array}{l}4015(654 \\
-13914)\end{array}$ \\
\hline Killip Class I & $24(57.1 \%)$ & $23(71.8 \%)$ & $1(10 \%)$ \\
\hline Killip Class II/III & $18(42.9 \%)$ & $9(28.2 \%)$ & 9(90\%) \\
\hline Killip Class IV & 0 & 0 & 0 \\
\hline
\end{tabular}

Table 2: Angiographic and $\mathrm{PCl}$ data.

\begin{tabular}{|c|c|c|c|}
\hline & $\begin{array}{l}\text { Total } \\
(n=42)\end{array}$ & $\begin{array}{l}\text { Survivors } \\
(n=32)\end{array}$ & $\begin{array}{c}\text { Non- } \\
\text { Survivors } \\
(n=10)\end{array}$ \\
\hline \multicolumn{4}{|l|}{ Culprit LMCA Lesion } \\
\hline LMCA Stenosis ostial & $8(19 \%)$ & $6(18.8 \%)$ & $2(20 \%)$ \\
\hline LMCA Stenosis midshaft & $5(11.9 \%)$ & $4(12.5 \%)$ & $1(10 \%)$ \\
\hline LMCA Stenosis distal & $26(61.9 \%)$ & $20(62.5 \%)$ & $6(60 \%)$ \\
\hline LMCA Stenosis ostial + distal & $3(7.1 \%)$ & $2(6.25 \%)$ & $1(10 \%)$ \\
\hline $\begin{array}{l}\text { LMCA Stenosis severity pre-PCl \% } \\
\text { (median, range) }\end{array}$ & $90(70-100)$ & $90(70-100)$ & 93 (70-99) \\
\hline \multicolumn{4}{|l|}{ Co-involvement of other lesions } \\
\hline LMCA distal + LCX & 5 (11.9\%) & $5(15.6 \%)$ & 0 \\
\hline LMCA distal + LAD & $9(21.4 \%)$ & $9(28.1 \%)$ & 0 \\
\hline LMCA distal + LAD + LCX & $11(26.2 \%)$ & $7(15.6 \%)$ & $4(40 \%)$ \\
\hline \multicolumn{4}{|l|}{ Stents } \\
\hline DES & $36(85.7 \%)$ & $26(81.2 \%)$ & $10(100 \%)$ \\
\hline BMS & $6(14.3 \%)$ & $6(18.8 \%)$ & 0 \\
\hline Stent diameter mm (median, range) & $4(3-5)$ & $4(3-5)$ & $4(3-4)$ \\
\hline Stent length $\mathrm{mm}$ (median, range) & $18(9-32)$ & $18(12-32)$ & $23(9-24)$ \\
\hline \multicolumn{4}{|l|}{$\mathrm{PCl}$ final result (median, range) } \\
\hline LMCA residual stenosis & $2(4.7 \%)$ & $0(0 \%)$ & $2(20 \%)$ \\
\hline LAD ostial residual stenosis \% & $22(52.4 \%)$ & $16(50 \%)$ & $6(60 \%)$ \\
\hline LCX ostial residual stenosis \% & $8(19 \%)$ & $4(12.5 \%)$ & $4(40 \%)$ \\
\hline \multicolumn{4}{|l|}{ Hemodynamics (median, range) } \\
\hline LVEF \% & $\begin{array}{c}48.2 \\
(12-75)\end{array}$ & $\begin{array}{c}50.9 \\
(12-75)\end{array}$ & $39.5(20-50)$ \\
\hline Peak systolic pressure $\mathrm{mm} \mathrm{Hg}$ & $\begin{array}{c}107.3 \\
(63-151)\end{array}$ & $\begin{array}{c}105.6 \\
(63-131)\end{array}$ & $\begin{array}{l}111.7(76- \\
151)\end{array}$ \\
\hline LVEDP & $\begin{array}{c}18.1 \\
(12-26)\end{array}$ & $\begin{array}{c}18.1 \\
(12-26)\end{array}$ & $21.0(16-26)$ \\
\hline IABP & $23(54.7 \%)$ & $15(46.9 \%)$ & $8(80 \%)$ \\
\hline
\end{tabular}

glycoprotein IIb/IIIa inhibitors, and the type of stents used were left to the discretion of the operator. In 36 cases (85.7\%) DES was used and in 6 cases (14.3\%) BMS was used.

\section{Statistical analyses}

Given the relatively small sample size of the analyzed patient population $(n=42)$, we used descriptive statistics to compare ECG abnormalities in survivors with those in the non-survivors. To compare the ECG abnormalities in these subgroups we used ChiSquare Test and Fisher Exact Test.

\section{Results}

The baseline clinical characteristics are presented in Table 1. The mean age of the total population $(n=42)$ was 70 years. Within this population $71.4 \%$ were men, $38.1 \%$ had a past medical history of myocardial infarction, and $21.4 \%$ had undergone a prior PCI. On admission to hospital the majority (57.1\%) was on aspirin, roughly a third on clopidogrel, and $50 \%$ on beta-blockers. All included patients clinically presented with ACS and $60 \%$ of them presented with ST elevated myocardial infarction (STEMI). The mean creatine kinase for the total study population was $2174 \mathrm{U} / \mathrm{l}$. The mean NT-proBNP 
Citation: Krasniqi N, Horisberger S, Siegrist PT, Fuchs TA, Saguner AM, et al. Analysis of Admission Electrocardiographic Patterns in Survivors and Non-Survivors of Unprotected Left Main Acute Coronary Syndrome Undergoing Percutaneous Coronary Intervention. J Cardiobiol. $2014 ; 2(2)$ : 5.

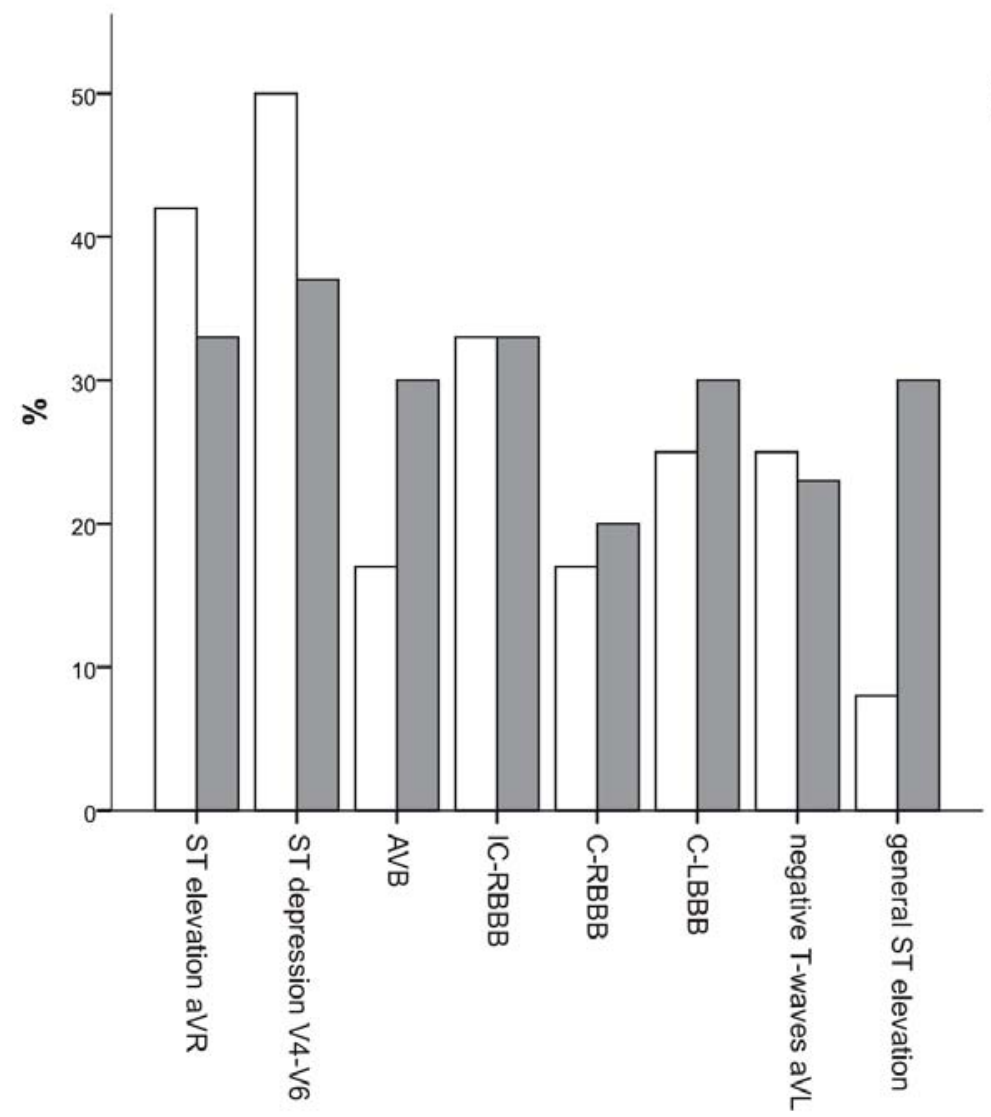

Figure 1: ECG abnormalities on admission (survivors vs. non-survivors).

AVB: Atrio-Ventricular Block; IC-RBBB: Incomplete Right Bundle Branch Block; C-RBBB: Complete Right Bundle Branch Block: C-LBBB: Complete Left Bundle Branch Block

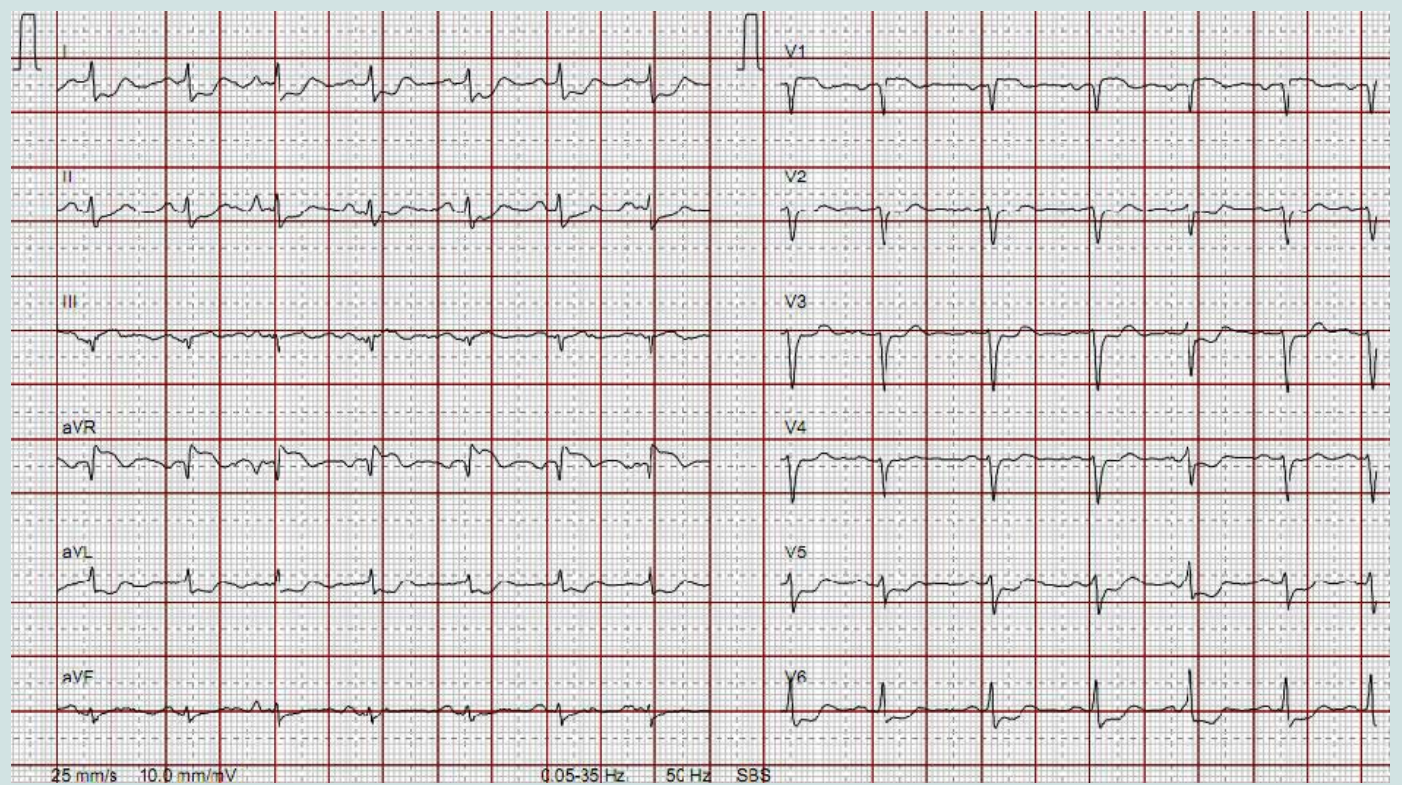

Figure 2: An ECG showing ST-elevation in aVR and V1, and ST-depression in anterolateral leads in a patient with left main coronary artery distal occlusion combined with LAD and LCX stenosis. 
Citation: Krasniqi N, Horisberger S, Siegrist PT, Fuchs TA, Saguner AM, et al. Analysis of Admission Electrocardiographic Patterns in Survivors and Non-Survivors of Unprotected Left Main Acute Coronary Syndrome Undergoing Percutaneous Coronary Intervention. J Cardiobiol. 2014;2(2): 5.

in the survivor subgroup was $2827 \mathrm{ng} / \mathrm{l}$ and in the non-survivor subgroup it was $4015 \mathrm{ng} / \mathrm{l} .24$ patients classified as Killip I and 18 patients classified as Killip II/III, no patients classified as Killip IV. On admission nine non-survivors presented with high Killip Class (II/III). The mean troponin level in the survivor subset was $5.8 \mu \mathrm{g} / \mathrm{l}$, but $16 \mu \mathrm{g} / \mathrm{l}$ in the non-survivor subgroup.

The mortality in patients with acute interventions in symptomatic LAD stenosis was $23.8 \%$ (10 patients).

In all cases the treated left main culprit lesion was unprotected (by collateral coronary blood flow or functional bypass grafts). Specifically, not a single patient had a history of a preceding CABG procedure or angiographically proven relevant collateralization to the left anterior descending or circumflex arteries.

Table 2 shows the characteristics of the left main culprit lesion, information about the stents used, the PCI final results, and hemodynamic data. In the total population and the subgroups of survivors and non-survivors, the majority had distal LM disease: $61.9 \%$, 59.3\%, and 60\%, respectively. Four non-survivors (40\%) had distal LM disease that was associated with significant proximal LAD and LCX lesions, whereas this could be demonstrated in only $15.6 \%$ of the survivors. The median stenosis severity of the left main coronary artery was $90 \%$ in the survivors and $93 \%$ in the non-survivor subgroup. The final results after left main PCI demonstrated excellent success rates on post intervention angiography. There was not a single patient with residual LM stenosis in the survivor subset. This was also true in 8 of the 10 patients who succumbed in hospital or during the follow-up period; the remaining two had a residual $80 \%$ LM stenosis. However, after PCI $\geq 70 \%$ residual ostial LAD stenosis could be demonstrated in $50 \%$ of the survivors and $60 \%$ of the non-survivors. Concerning residual ostial LCX stenosis, the percentages were $12.5 \%$ in the survivors and $40 \%$ in the non-survivors, respectively.

On hemodynamic assessment the survivor group had a seemingly higher mean left ventricular ejection fraction (50.9\% versus $39.5 \%)$ as determined on left ventricular angiography.

Figure 1 and Figure 2 present ECG patterns on admission. To compare the ECG patterns differences between subgroups we used the chi-square test and fisher exact test. A p value $<0.05$ was considered statistically significant. Given the small sample size there were no significant ECG patterns differences between survivors and non-survivors (Table 3 ).

The most common ECG patterns were ST-segment elevation in aVR, ST-segment depression in V4-V6, AV block, and RBBB. In patients with distal left main stenosis the most common ECG pattern was ST-segment elevation in aVR (16 patients, 61.5\%).

Significant ST-segment elevation in aVR, significant lead V4-V6 ST-segment depression, and AV block were most common in patients with distal LM stenosis combined with ostial LAD- and LCX-stenosis (7 patients, $63.6 \%$ of all patients with distal LM stenosis combined with ostial LAD- and LCX-stenosis). Using descriptive analysis there were higher proportions of ST-segment elevations in lead aVR and significant V4-V6 ST-segment depressions in the non-survivor subgroup: for both alterations $42 \%$ / 50\% versus $33 \%$ / $37.3 \%$ in the survivor subset. First degree AV block was more prevalent in the
Table 3: Chi-Square Test and Fisher Exact Test to compare the ECG patterns differences between survivors and non-survivors. A $p$ value $<0.05$ was considered statistically significant.

\begin{tabular}{|l|c|c|c|}
\hline & Fisher Exact & $\begin{array}{c}\text { Chi Square with } \\
\text { Yates correction }\end{array}$ & $\begin{array}{c}\text { Chi Square } \\
\text { without Yates } \\
\text { correction }\end{array}$ \\
\hline ST Elevation AVR & 0.73 & 0.88 & 0.61 \\
\hline $\begin{array}{l}\text { ST- Depression } \\
\text { V4-V6 }\end{array}$ & 0.50 & 0.65 & 0.43 \\
\hline AVB & 0.46 & 0.62 & 0.37 \\
\hline RBB & 1.0 & 0.80 & 0.80 \\
\hline LBB & 1.0 & 0.75 & 0.75 \\
\hline T neg avL & 1.0 & 0.91 & 0.91 \\
\hline ST-Elevation & 0.23 & 0.28 & 0.14 \\
\hline
\end{tabular}

survivor subgroup (30\%) than in the non-survivor subgroup (20\%). Two non-survivors (20\%) with distal LM disease that was associated with significant proximal LAD and LCX lesions showed a first degree AV block combined with significant ST-segment depression in V4V6

\section{Discussion}

Although CABG has been considered the gold standard for unprotected left main cardiac disease revascularization, more recently PCI has emerged as a possible alternative mode of revascularization in carefully selected patients [5]. Several studies have suggested that coronary stenting is feasible for patients with ULMCA stenosis [7]. Moreover, the results of recent randomized control trials suggest that major clinical outcomes in selected patients with ULMCA disease are similar between CABG and PCI at the 1- to 2-year follow-up, but that repeat revascularization rates are higher after PCI than after CABG $[8,9]$. However, randomized control trials with an extended followup of 5 years are required to provide definitive conclusions about the optimal treatment for ULMCA, but none have yet been conducted.

Some retrospective studies involving patients with ULMCA stenosis showed no significant differences in long-term all-cause and cardiac mortality between the CABG and DES groups [10,11]. In our analysis the cumulative mortality rate from hospitalization to 6 months post discharge in patients with acute PCI in symptomatic LAD stenosis was $23.8 \%$ (10 patients). Compared to the surgical revascularization strategy the mortality rate in our analysis was higher [1]. A possible explanation for the higher mortality rate in our study could be attributed to the high proportion of patients presenting with STEMI (60\%). Montalescot et al. showed a cumulative mortality rate of $14 \%$ from time of hospitalization to 6 months after discharge, which was lower than in our study [1]. The proportion of patients with ongoing STEMI in the aforementioned study was 35\% compared to $60 \%$ in our study.

On hemodynamic assessment the non-survivor group seemingly had a lower mean left ventricular ejection fraction compared to the survivor group (39.5\% versus 50.9\%), as determined on left ventricular angiography, and a higher level of NT-proBNP (4015 ng/l versus $2827 \mathrm{ng} / \mathrm{l})$ and troponin $(16 \mu \mathrm{g} / \mathrm{l}$ versus $5.8 \mu \mathrm{g} / \mathrm{l})$. The higher levels of NT-proBNP in the non-survivors correspond to the higher proportion of patients with high Killip class in this subgroup (90\% versus $59 \%$ in the survivors' subgroup). 
Citation: Krasniqi N, Horisberger S, Siegrist PT, Fuchs TA, Saguner AM, et al. Analysis of Admission Electrocardiographic Patterns in Survivors and Non-Survivors of Unprotected Left Main Acute Coronary Syndrome Undergoing Percutaneous Coronary Intervention. J Cardiobiol. $2014 ; 2(2)$ : 5.

The analysis of ECG patterns in patients with acute coronary syndrome due to unprotected left main coronary artery (ULMCA) disease is underrepresented in current trials. There are only some small observational studies that have analyzed the ECG patterns in patients with acute coronary syndrome with unprotected left main coronary artery disease [13]. A detailed ECG analysis in patients with STEMI / NSTEMI is very important in order to show-at an early stage of the diagnostic process-the possibility of an ULMCA problem. Knotts et al. showed that diffuse ST-segment depression combined with ST-segment elevation in aVR is not always caused by left main coronary artery disease [14]. In our analysis we observed high proportions of significant ST-segment elevation in aVR combined with significant V4-V6 ST-segment depression in patients with acute left main coronary artery disease.

Fiol et al. showed that ST elevations in patients with acute left main disease are similar to LAD occlusion. They also described in their series a complete RBBB combined with superoanterior hemiblock [15]. In this small analysis only 3 of 7 analyzed patients (43\%) survived. We observed a higher rate of ST-elevation in aVR combined with ST-depression in V4-V6 in the non-survivor subgroup. Significant ST-segment elevation in aVR, significant STsegment depression in V4-V6, and AV block were most common in patients with distal LM stenosis combined with ostial LAD- and LCX-stenosis (7 patients, $63.6 \%$ of all patients with distal LM stenosis combined with ostial LAD- and LCX-stenosis). Four patients with such an ECG pattern were non-survivors.

In our study with a small sample size and limited cases there were no specific ECG patterns on admission that could have been indicative of an adverse outcome in ACS patients related to an unprotected left main culprit lesion.

The present analysis had several limitations. This study was not a prospective, randomized study, and the sample size was small. A larger dataset is needed to confirm the findings of our analysis.

\section{References}

1. Montalescot G, Brieger D, Eagle KA, Anderson FA Jr, FitzGerald G, et al (2009) Unprotected left main revascularization in patients with acute coronary syndromes. Eur Heart J 30: 2308-2317.

2. Pedrazzini GB, Radovanovic D, Vassalli G, Sürder D, Moccetti T, et al. (2011) Primary percutaneous coronary intervention for unprotected left main disease in patients with acute ST-segment elevation myocardial infarction the AMIS (Acute Myocardial Infarction in Switzerland) plus registry experience. JACC Cardiovasc Interv 4: 627-633
3. Hamm CW, Bassand JP, Agewall S, Bax J, Boersma E, et al. (2011) ESC Guidelines for the management of acute coronary syndromes in patients presenting without persistent ST-segment elevation: The Task Force for the management of acute coronary syndromes (ACS) in patients presenting without persistent ST-segment elevation of the European Society of Cardiology (ESC). Eur Heart J 32: 2999-3054.

4. Task Force on the management of ST-segment elevation acute myocardial infarction of the European Society of Cardiology (ESC), Steg PG, James SK, Atar D, Badano LP, et al. (2012) ESC Guidelines for the management of acute myocardial infarction in patients presenting with ST-segment elevation. Eur Heart J 33: 2569-2619.

5. Nikus KC, Eskola MJ, Virtanen VK, Vikman S, Niemelä KO, et al. (2004) STdepression with negative T waves in leads V4-V5--a marker of severe coronary artery disease in non-ST elevation acute coronary syndrome: a prospective study of Angina at rest, with troponin, clinical, electrocardiographic, and angiographic correlation. Ann Noninvasive Electrocardiol 9: 207-214.

6. Nikus KC, Sclarovsky S, Huhtala H, Niemelä K, Karhunen P, et al. (2012) Electrocardiographic presentation of global ischemia in acute coronary syndrome predicts poor outcome. Ann Med 44: 494-502.

7. Park SJ, Park DW (2009) Percutaneous coronary intervention with sten implantation versus coronary artery bypass surgery for treatment of left main coronary artery disease: is it time to change guidelines? Circ Cardiovasc Interv 2: 59-68.

8. Buszman PE, Kiesz SR, Bochenek A, Peszek-Przybyla E, Szkrobka I, et al. (2008) Acute and late outcomes of unprotected left main stenting in comparison with surgical revascularization. J Am Coll Cardiol 51: 538-545.

9. Park SJ, Kim YH, Park DW, Yun SC, Ahn JM, et al. (2011) Randomized trial of stents versus bypass surgery for left main coronary artery disease. N Engl J Med 364: 1718-1727

10. Lee MS, Jamal F, Kedia G, Chang G, Kapoor N, et al. (2007) Comparison of bypass surgery with drug-eluting stents for diabetic patients with multivessel disease. Int J Cardiol 123: 34-42.

11. Daemen J, Wenaweser P, Tsuchida K, Abrecht L, Vaina S, et al. (2007) Early and late coronary stent thrombosis of sirolimus-eluting and paclitaxel-eluting stents in routine clinical practice: data from a large two-institutional cohort study. Lancet 369: 667-678.

12. Jong GP, Ma T, Chou P, Shyu MY, Tseng WK, et al. (2006) Reciprocal changes in 12-lead electrocardiography can predict left main coronary artery lesion in patients with acute myocardial infarction. Int Heart J 47: 13-20.

13. Knotts RJ, Wilson JM, Kim E, Huang HD, Birnbaum Y (2013) Diffuse ST depression with ST elevation in aVR: Is this pattern specific for global ischemia due to left main coronary artery disease? J Electrocardiol. 46: 240248

14. Fiol M, Carrillo A, Rodríguez A, Pascual M, Bethencourt A, et al. (2012) Electrocardiographic changes of ST-elevation myocardial infarction in patients with complete occlusion of the left main trunk without collateral circulation: differential diagnosis and clinical considerations. J Electrocardiol 45: 487-490.

\section{Acknowledgements}

Dr. Nazmi Krasniqi and Dr. Stephanie Horisberger has contributed equally to this work. 